\title{
A study of interface reaction zone in a SiC fibre /Ti-17 composite
}

DOI:

10.1016/j.micron.2018.07.003

\section{Document Version}

Accepted author manuscript

Link to publication record in Manchester Research Explorer

\section{Citation for published version (APA):}

Fan, Y., \& Zhou, X. (2018). A study of interface reaction zone in a SiC fibre /Ti-17 composite. Micron, 113, 91-98. https://doi.org/10.1016/j.micron.2018.07.003

\section{Published in:}

Micron

\section{Citing this paper}

Please note that where the full-text provided on Manchester Research Explorer is the Author Accepted Manuscript or Proof version this may differ from the final Published version. If citing, it is advised that you check and use the publisher's definitive version.

\section{General rights}

Copyright and moral rights for the publications made accessible in the Research Explorer are retained by the authors and/or other copyright owners and it is a condition of accessing publications that users recognise and abide by the legal requirements associated with these rights.

\section{Takedown policy}

If you believe that this document breaches copyright please refer to the University of Manchester's Takedown Procedures [http://man.ac.uk/04Y6Bo] or contact uml.scholarlycommunications@manchester.ac.uk providing relevant details, so we can investigate your claim.

\section{OPEN ACCESS}




\section{Accepted Manuscript}

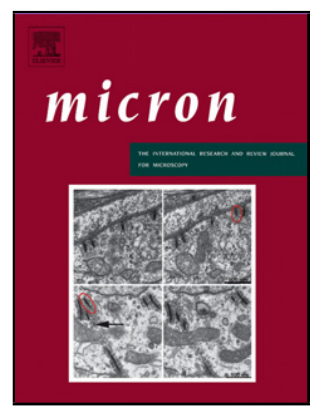

Title: A study of interface reaction zone in a SiC fibre /Ti-17 composite

Authors: Yingwei Fan, Xiaorong Zhou

PII: $\quad$ S0968-4328(18)30226-9

DOI: $\quad$ https://doi.org/10.1016/j.micron.2018.07.003

Reference: $\quad$ JMIC 2582

To appear in: $\quad$ Micron

Received date: $\quad 1-6-2018$

Revised date: $\quad 8-7-2018$

Accepted date: $\quad$ 8-7-2018

Please cite this article as: Fan Y, Zhou X, A study of interface reaction zone in a SiC fibre /Ti-17 composite, Micron (2018), https://doi.org/10.1016/j.micron.2018.07.003

This is a PDF file of an unedited manuscript that has been accepted for publication. As a service to our customers we are providing this early version of the manuscript. The manuscript will undergo copyediting, typesetting, and review of the resulting proof before it is published in its final form. Please note that during the production process errors may be discovered which could affect the content, and all legal disclaimers that apply to the journal pertain. 


\section{A study of interface reaction zone in a $\mathrm{SiC}$ fibre /Ti-17 composite}

Yingwei Fan ${ }^{1,2}$, Xiaorong Zhou ${ }^{2, *}$

${ }^{1}$ AECC Beijing Institute of Aeronautical Materials, Beijing Key Laboratory of Aeronautical Materials Testing and Evaluation, Aviation Key Laboratory of Science and Technology on Materials Testing and Evaluation, Key Laboratory of Aeronautical Materials Testing and Evaluation, Aero Engine Corporation of China, Beijing, 100095, China. Email: yingei.fan@yahoo.com

${ }^{2}$ School of Materials, University of Manchester, Manchester, M13 9PL, United Kingdom. Tel: +44 (0) 1613064832. E-mail address: xiaorong.zhou@ manchester.ac.uk * Corresponding author. AECC Beijing Institute of Aeronautical Materials, Beijing, 100095, China. Tel: +86 13810635252. E-mail address: yingwei.fan@yahoo.com

\section{Highlights}

- A well-defined two-layered reaction zone is formed at the fibre/matrix interface

- $\mathrm{Al}, \mathrm{Mo}$ and $\mathrm{Cr}$ in the matrix are rejected out of the reaction zone and piled up

- $\mathrm{Zr}$ and $\mathrm{Sn}$ are present within the coarse-grained region of the reaction zone

- A structural model proposed for the formation mechanism of reaction zone

\section{ABSTRACT}

The interface reaction zone (RZ) in a unidirectional continuous carbon-coated SiC fibre reinforced Ti-17 titanium alloy composite is investigated. Micro-computed tomography (CT), scanning and transmission electron microscopy are employed to characterize the fibre/matrix interface. It is revealed that the interface $\mathrm{RZ}$ is a $400 \mathrm{~nm}$ thick titanium carbide (TiC) layer which is composed of two sublayers, a $60 \mathrm{~nm}$ thick fine-grained 
sublayer and an approximate $340 \mathrm{~nm}$ thick coarse-grained sublayer. The $\mathrm{RZ}$ is formed through chemical reaction between carbon coating on the SiC fibre surface and $\mathrm{Ti}, \mathrm{Zr}$ and $\mathrm{Sn}$ in the alloy matrix. The reaction is controlled by atom diffusion occurring at the fibre/matrix interface. However, in the reaction process, $\mathrm{Al}, \mathrm{Cr}$ and $\mathrm{Mo}$ in the matrix are rejected and piled up in front of the RZ on the matrix side. A structure model is proposed to describe the formation mechanism of the interface RZ.

Key words: Metal matrix composite; Reaction zone; Diffusion; Interface structure This work was financially supported by the National Key R \& D Program of China ( grant number 2017YFA0403704 ).

\section{Introduction}

Unidirectional continuous fibre reinforced titanium alloy matrix composites (TMCs) have gained significant attractiveness for material researchers and engineers since they were initially proposed in 1960s due to their high specific strength, stiffness and fatigue and creep resistance, consequently, the possibility of marked weight reductions of 30-70\% compared to titanium alloys, steels or nickel-based superalloys. The TMCs give rise to interests of the potential applications in the compressor stage of aero engines (Campbell, 2012; Chou et al., 1985; Lissenden et al., 1995; Saito, 2004; Singerman and Jackson, 1996; Takahashi et al., 2012; Vassel, 1997). 
In determining the processing/manufacturing parameters and macroscopic performance of the TMCs, fibre/matrix interface plays a critical role since the fibre and matrix are interconnected and interactive at such interface. Therefore, investigations have been largely focused on the interface in order to improve TMC processing/manufacturing technology and, consequently, its performance. For example, by investigating the interfacial reaction phenomena, the stability and compatibility of the relevant materials can be evaluated. The outcome of such evaluation provides the necessary knowledge for interface design in TMCs for optimising the processing/manufacturing technology and improving product performance (Fromentin et al., 1996; Lacoste et al., 2015; Li et al., 2011; Ngai et al., 2011; Yang et al., 1998b).

Multi-layered reaction zone at the fibre/matrix interface has been observed in various titanium alloy matrix composites reinforced by SiC fibre with protective carbon-rich coating in previous investigations. The RZ commonly contains titanium carbides due to the chemical reaction between carbon and titanium (Dudek et al., 1997; Hall and Ni, 1995; Lacoste et al., 2015; Yang and Dudek, 1997; Yang et al., 1998b). Other phases, such as titanium silicides, were also identified in the RZ due to the reaction between titanium and silicon in the carbon-rich coating (Dudek et al., 1997; Hall and Ni, 1995; Yang and Dudek, 1997; Yang et al., 1998b). In addition, titanium aluminium carbide may also be present in the RZ owing to the reaction between carbon and titanium/aluminum in the alloy matrix, for example, Ti-25Al-10Nb-3V-1Mo matrix (Hall and Ni, 1995; Yang and Dudek, 1997; Yang et al., 1998b). The structure of the interface RZ varies significantly depending on the elemental components of both protective carbon coating on SiC fibre surface and matrix alloy. The other critical factor that influences the RZ structure is the fabrication process of the composites (Dudek et 
al., 1997; Fan et al., 1997; Guo et al., 1998; Lacoste et al., 2015; Zhang et al., 2014; Zhang et al., 2013; Zhao et al., 2013). Thus, in the present study, the interface RZ in a SiC fibre reinforced Ti-17 matrix composite newly developed by Aero Engine Corporation of China (AECC) is investigated in order that its characteristic structure can be fully understood, which is essential for optimising the fabrication process and the property of the composite.

Further, chemical reaction at the fibre/matrix interface takes place through atom diffusion which is driven by the difference in chemical potential formed by the element concentration gradient at the interface. Therefore, investigation on the atom diffusion across the interface is also the focus in the field (Guo et al., 1998; Guo et al., 1993; Hall and Lirn, 1992; Jeng et al., 1989; Martineau et al., 1984; Metcalfe, 1974; Naka et al., 1997; Xun et al., 2000; Zhang et al., 2014). But very few studies investigate the behaviour of non-reactive atoms in the regions adjacent to the RZ. To the best of the authors' knowledge, only the rejection of aluminium by the $\mathrm{RZ}$ in the $\mathrm{C}$-coated or $\mathrm{B}_{4} \mathrm{C}$ /boron-coated SiC fibre reinforced titanium composites has been reported (Hall and Lirn, 1992; Jeng et al., 1989; Martineau et al., 1984; Metcalfe, 1974). In order to further understand the interfacial diffusivity of the alloying elements in the Ti-17 alloy, and their contribution to the interface reaction and stability, the present study also investigates the diffusion phenomena of all the alloying elements at the fibre/matrix interfacial region in the composite. A structural model is proposed to describe the formation mechanism of the reaction zone at fibre/matrix interface and the associated atom diffusion. 


\section{Experimental}

The composite investigated in this study is a unidirectional continuous SiC fibre reinforced titanium alloy Ti-17 (Ti-5Al-2Sn-2Zr-4Cr-4Mo) composite, which is fabricated using matrix coated fibre (MCF) route followed by hot isostatic pressing (HIP) at $860^{\circ} \mathrm{C} / 180 \mathrm{MPa}$ for $30 \mathrm{~min}$. The HIP temperature is the typical forging temperature to achieve equiaxed $\alpha$ structures in the matrix alloy. The diameter of the MCF before HIP is $150 \mu \mathrm{m}$. The final dimension of the composite bar is $15 \mathrm{~mm}$ (diameter). Ti-17 is selected as the matrix alloy due to its good tensile properties, creep resistance and fracture toughness over other titanium alloys such as Ti-6Al-4V, which is mainly used for the manufacturing of fan blades and compressor disks of aero engine. The SiC fibre of $100 \mu \mathrm{m}$ diameter has a tungsten core of $14 \mu \mathrm{m}$ diameter and $1 \mu \mathrm{m}$ thick pure carbon coating. A high fibre volume fraction is employed for improvement of thermal and mechanical responses of the composite and more weight saving.

Fibre distribution in the composite was investigated using X-ray micro-computed tomography operated at $140 \mathrm{keV}$. Totally 1800 projections were acquired for 3D reconstruction. The morphology and chemical composition of interface RZ were characterised by scanning electron microscopy (SEM) with angle-selective backscattered (AsB) electron detector under $8 \mathrm{kV}$ and energy dispersive $\mathrm{X}$-ray spectroscopy (EDS) under $15 \mathrm{kV}$. Transmission electron microscopy (TEM) with EDS and selected area electron diffraction (SAED) were also employed under $300 \mathrm{kV}$ to investigate the morphology, chemical composition and crystal structure of the RZ at the fibre/matrix interface. 
Samples used for SEM examination were mechanically ground and polished with $3 \mu \mathrm{m}$ finish. The polished sample surface was cleaned with plasma using a glow discharge optical emission spectroscopy (GDOES) instrument at an argon pressure of 600Pa and applied voltage of $35 \mathrm{~V}$ with a power of $25 \mathrm{~W}$ for 10 s. The GDOES sputtering was employed to remove the contamination and artificial defects caused by deformation during mechanical grinding and polishing. Meanwhile the microstructure was revealed by the sputtering due to the sputtering rate variation at different microscopic sites with different elements concentrations and crystal structure. As for TEM specimens, $0.2 \mathrm{~mm}$ thick slices were taken from the block samples perpendicular to the fibre axis using low-speed diamond blades. The slices were then mechanically ground and polished on both sides with $0.25 \mu \mathrm{m}$ finish until the thickness is smaller than $0.1 \mathrm{~mm}$. The slices were finally punched into discs of $3 \mathrm{~mm}$ in diameter and milled in a precision ion polishing system (PIPS) at $4 \sim 6^{\circ}$ tilt and $6 \mathrm{keV}$ for 6 hours until the disc is electron transparent in TEM under the accelerating voltage of $300 \mathrm{kV}$.

\section{Results and discussion}

The distribution of the carbon coated $\mathrm{SiC}$ fibres in the Ti-17 alloy matrix is shown in Figure 1 and Figure 2. The fibres are statistically uniformly arranged in the composite although the fibre spacing varies at some local sites on microscopic scale (Figure 2). The reconstructed 3D X-ray micro-CT image (Figure 1) demonstrates the configuration of the components in the composite. The Ti-17 matrix is transparent and the carbon coated SiC fibres are green with colour code R: 64, G: 227, B: 210 with red tungsten cores colour coded in R: 255, G: 0, B: 0. Figure 1 also shows clearly that the fibres are 
not distorted or kinked in axis direction during fabrication. Direct impingement between the neighbouring fibres is not found on microscopic scales (Figure 2).

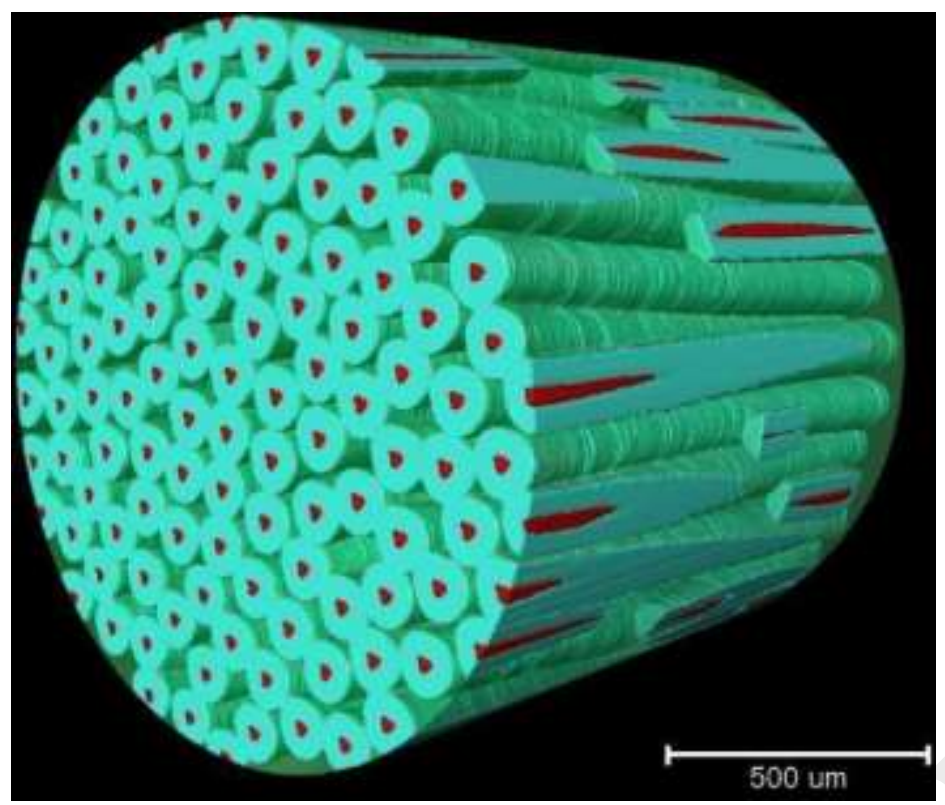

Figure $1 \mathrm{X}$-ray 3D volumetric reconstruction showing the fibre distribution.

Transparency is applied to the alloy matrix, and carbon coated $\mathrm{SiC}$ fibres are green with colour code R: 64, G: 227, B: 210 and tungsten cores are red with colour code R: 255, G: $0, \mathrm{~B}: 0$.

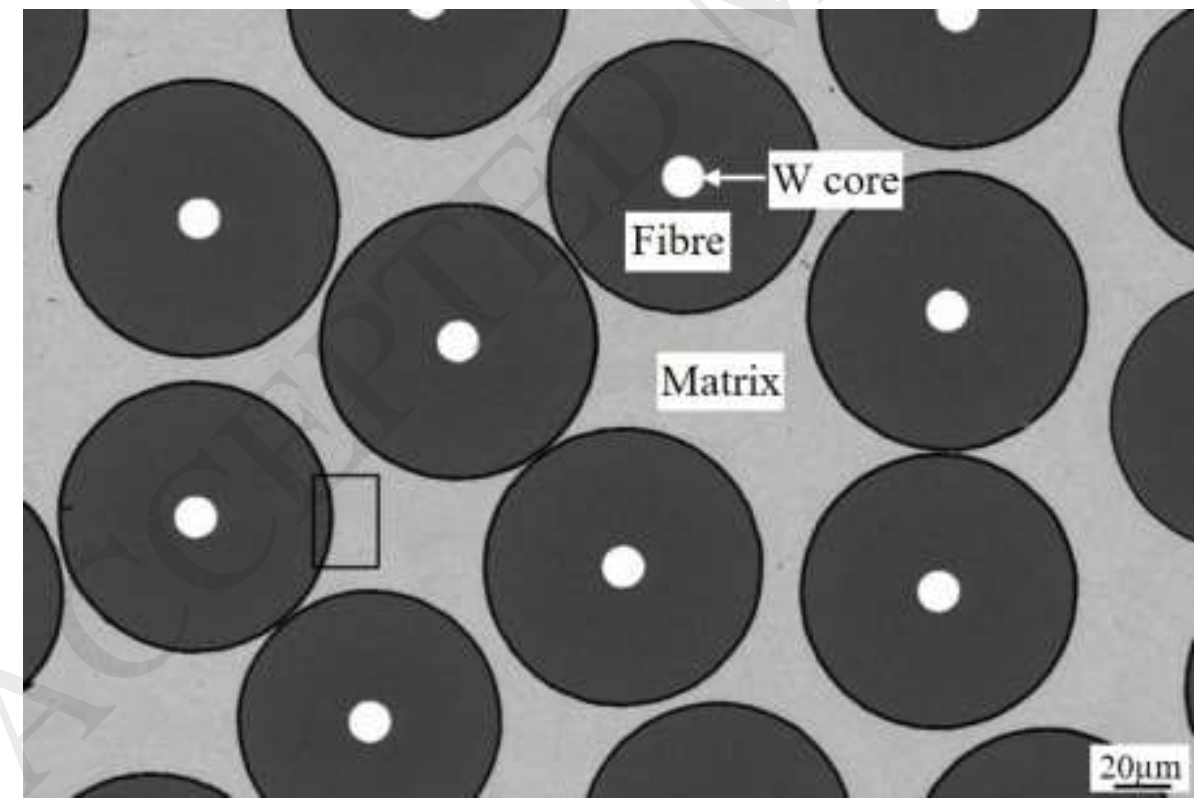

Figure 2 Scanning electron micrograph of the cross section of the composite, showing the overview of the fibre distribution. 
The volume fraction of the fibres is determined to be $69.6 \%$ based on the $3 \mathrm{D}$ volumetric reconstruction. The calculated average fibre spacing is $113.2 \mu \mathrm{m}$ using Equation 1 (Hull and Clyne, 1996) based on the above measurement of fibre volume fraction.

$$
V_{f}=\frac{\pi}{2 \sqrt{3}}\left(\frac{R_{f}}{0.5 S}\right)^{2}
$$

where $V_{f}$ is the fibre volume fraction, $R_{f}$ is the radius of the fibre and $S$ is the fibre spacing which is described by the centre to centre distance between two neighbouring fibres in the idealised hexagonal arrangement of the fibres.

The typical structure of the fibre/matrix interface is shown in Figure 3 (a) which is obtained from the framed area in Figure 2. Figure 3 (b) shows the framed area in Figure 3 (a) at an increased magnification, illustrating the interfacial region between the $\mathrm{C}$ coating on the fibre and the alloy matrix. The protective carbon coating on the SiC fibre surface can be seen clearly. The measured average thickness of the carbon coating is $1.33 \mu \mathrm{m}$ with the maximum value of $1.36 \mu \mathrm{m}$ and minimum value of $1.31 \mu \mathrm{m}$. A welldefined reaction zone is evident immediately across the C coating/matrix interface on the matrix side. The composition and structure of the reaction zone is characterized in TEM and discussed later. Larger $\alpha$ and $\beta$ phase grains are present in the matrix adjacent to the $\mathrm{RZ}$ in comparison with the grains in the bulk matrix. The two phases can be differentiated based on the fact that $\alpha$ phase is rich in $\mathrm{Al}$ while $\beta$ phase is rich in Mo and Cr. Thus, $\alpha$ phase appears relatively dark while $\beta$ phase appear relatively bright in the backscattered electron image. Five measurements were made for the chemical composition of each phase using EDS. The average value together with its standard deviation is presented in Table 1 , revealing that in either $\alpha$ phase or $\beta$ phase, the content 
of $\mathrm{Al}, \mathrm{Cr}$ and $\mathrm{Mo}$ in the region adjacent to the $\mathrm{RZ}$ is much higher than that within the bulk matrix. It is noteworthy that the $\mathrm{Al}$ content in $\alpha$ phase adjacent to the $\mathrm{RZ}$ has increased more than twofold in comparison with that in the $\alpha$ phase within the bulk matrix. The composition of Mo in the $\beta$ phase adjacent to the RZ is nearly three times as high as that in the $\beta$ phase within the bulk matrix.
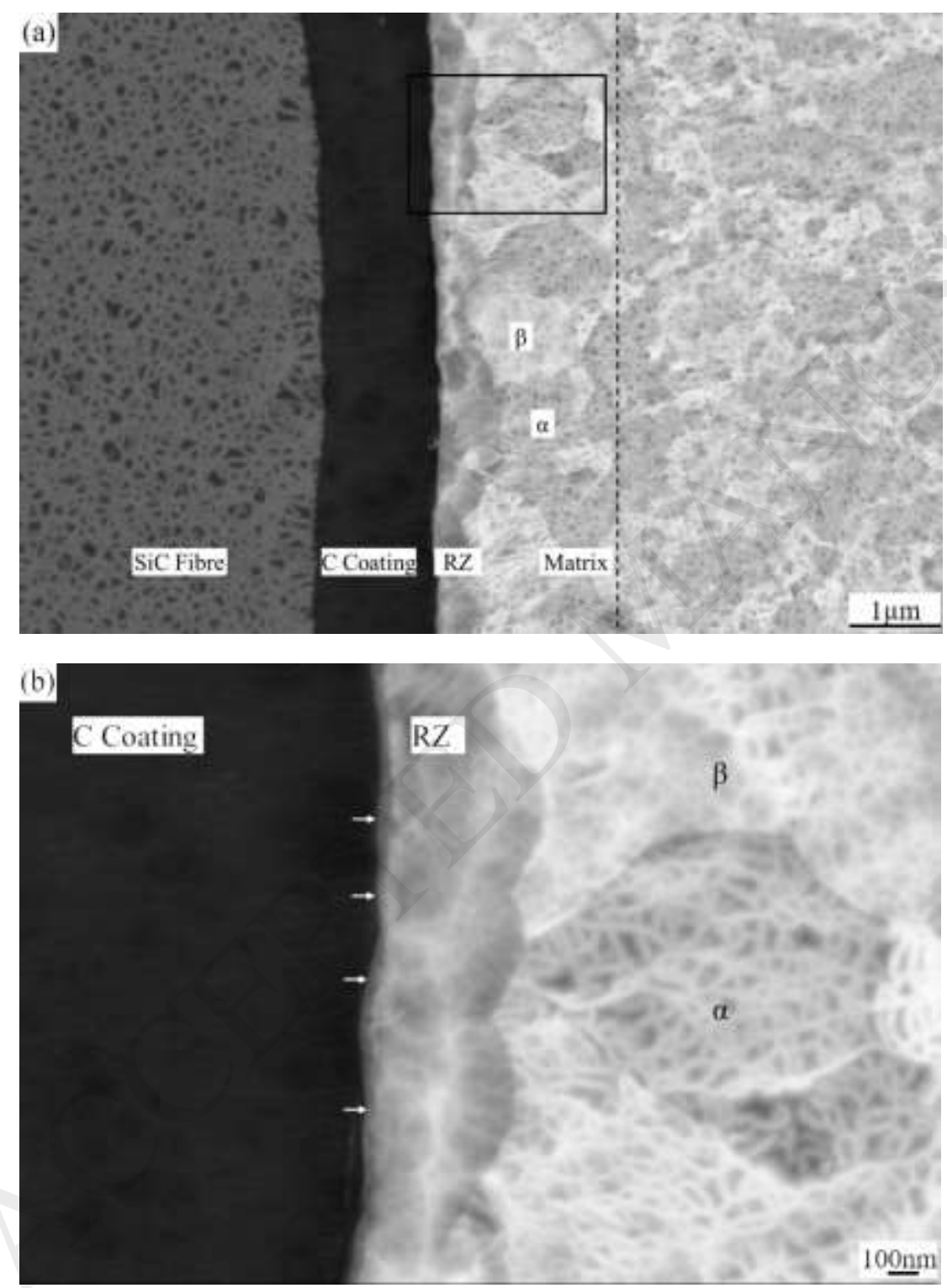

Figure 3 SEM micrographs of the fibre/matrix interfacial region in the composite: (a) the interfacial structure of the framed area indicated in Figure 2 at an increased magnification and (b) the framed area indicated in (a) at an increased magnification, showing the morphology of the interface region between $\mathrm{C}$ coating and matrix. 
Table 1 Compositions of $\alpha$ and $\beta$ phases at different areas in the composite

\begin{tabular}{llll}
\hline Mass fraction $(\%)$ & $\mathrm{Al}$ & Mo & $\mathrm{Cr}$ \\
\hline$\alpha$ phase next to RZ & $15.6 \pm 0.4$ & $4.2 \pm 0.1$ & $2.6 \pm 0.1$ \\
$\beta$ phase next to RZ & $2.7 \pm 0.3$ & $18.8 \pm 0.1$ & $10.0 \pm 0.2$ \\
$\alpha$ phase within bulk matrix & $7.9 \pm 0.2$ & $1.9 \pm 0.1$ & $1.8 \pm 0.1$ \\
$\beta$ phase within bulk matrix & $2.3 \pm 0.2$ & $6.8 \pm 0.1$ & $5.3 \pm 0.2$ \\
& & & \\
\hline
\end{tabular}

The relatively larger grains in the matrix adjacent to the RZ (Figure 3) are resulted from the recrystallization that occurred during material fabrication process, specifically in the HIP process under high temperature and pressure. The SiC fibre and Ti-17 alloy matrix have significantly different coefficients of thermal expansion (CTE), $2.6 \times 10^{-6} /{ }^{\circ} \mathrm{C}$ and $9.7 \times 10^{-6} /{ }^{\circ} \mathrm{C}$ respectively. The CTE of the matrix is nearly four times higher than that of the fibres. Thus, the local clamping stress at the interface and in the matrix region adjacent to the interface is much higher than that far away from interface due to the significant CTE mismatch between the alloy matrix and the reinforcing fibres (Bobet and Masuda, 1997; Mukherjee et al., 1997). In such case, the stored energy associated with the dislocations and sub-boundaries introduced by straining in the HIP process provides the driving force for the nucleation and growth of grains for recrystallization.

Scrutiny of Figure 3 (b) reveals a thin layer in the outmost region of the RZ, immediately next to the C coating, as indicated by the arrows. More details of the thin layer are revealed by TEM, as shown in Figure 4 (a). A grey layer is evident next to the carbon coating, which is an artefact formed by the deposition of alloy matrix when the sample was sputtered in the PIPS. The crack between the grey layer deposition and the 
$\mathrm{RZ}$ is also an artefact that was introduced during specimen preparation. The generation of these defects will be further discussed later. Figure 4 (a) shows that the RZ consists of two sublayers. The sublayer next to the crack (initially next to the carbon coating) has finer grains compared with the sublayer immediately adjacent to the matrix. The average thickness of the entire RZ is approximately $400 \mathrm{~nm}$ and the fine-grained sublayer is $60 \mathrm{~nm}$ in thickness.

In order to determine the crystal structure of the RZ, SAED was conducted on the two sites located in the fine-grained and the coarse-grained sublayer respectively, as indicated by the two circles denoted by 1 and 2 in Figure 4 (a). The patterns are illustrated in Figures 4(b) and (c) respectively. The selected area at site 1 includes many fine grains in the fine-grained sublayer in the RZ. Therefore, one set of polycrystalline diffraction rings is obtained, as shown in Figure 4 (b). As expected, one set of symmetrical diffraction spots is generated at site 2 as only one single big grain in the coarse-grained sublayer is selected, as shown in Figure 4 (c). The diffraction patterns indicate that the crystal structure of the $\mathrm{RZ}$ is the same as that for $\mathrm{TiC}$, which has a facecentred cubic structure with $\mathrm{a}=0.42 \mathrm{~nm}$. 


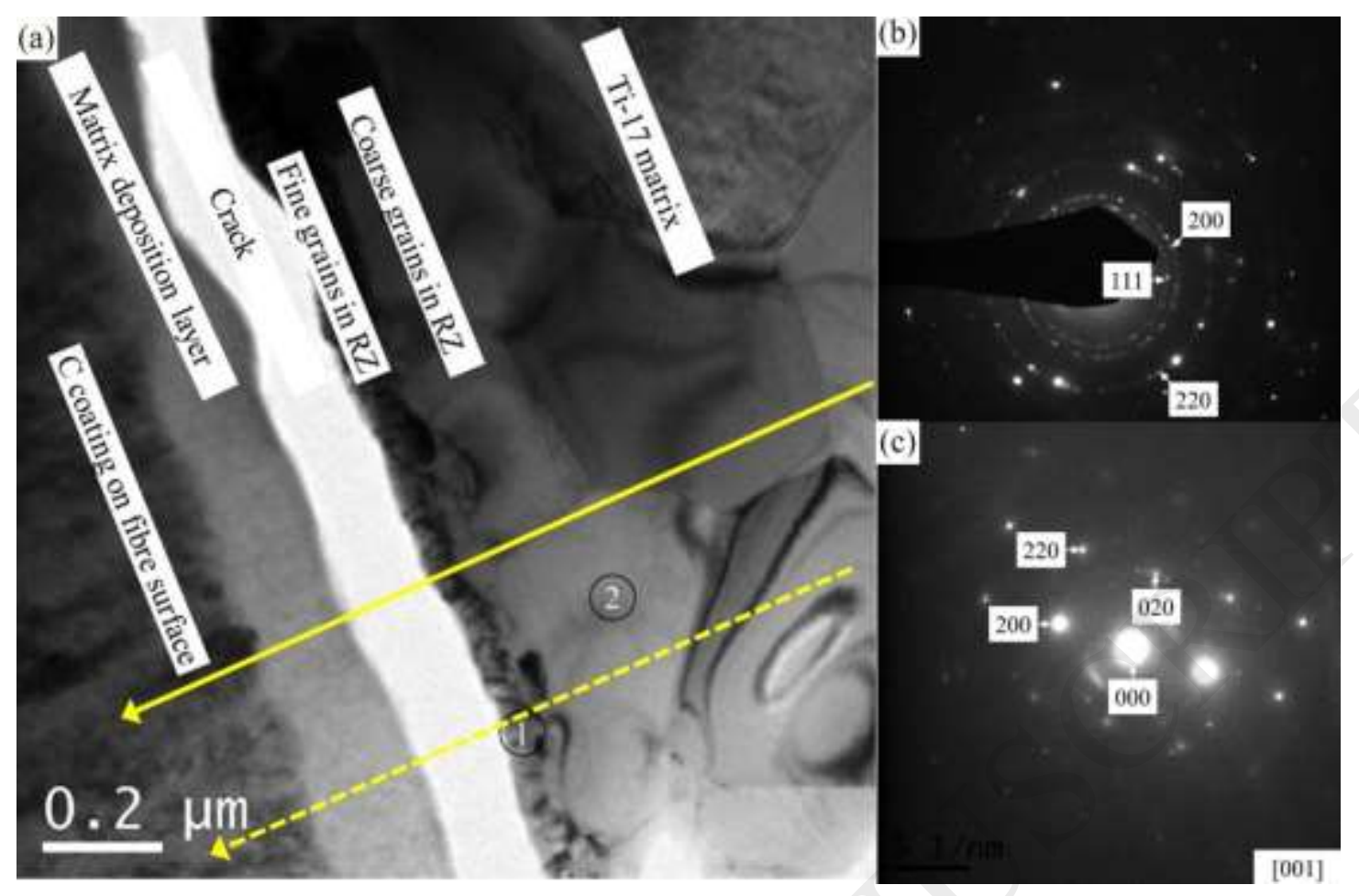

Figure 4 (a) Transmission electron micrograph of the interface between carbon coating and alloy matrix in the composite, and electron diffraction pattern at site 1 in the finegrained sublayer within the RZ (b) and at site 2 in the coarse-grained sublayer within the RZ in zone [001] (c).

Further, the composition of each sublayer in the RZ was analysed using EDS in TEM, as listed in Table 2. Five different measurements were made for each sublayer in the RZ so that the standard deviation of the measurements was evaluated. The elemental components in both sublayers are mainly $\mathrm{C}$ and $\mathrm{Ti}$ with a small amount of $\mathrm{Zr}$ and $\mathrm{Sn}$. The other major alloying elements $\mathrm{Mo}, \mathrm{Cr}$ and $\mathrm{Al}$ in the Ti-17 matrix are not found in the RZ. The contents of all the elements are similar in both sublayers. The contents of C in both sublayers are between $45 \%$ and $49 \%$. The composition of the $\mathrm{RZ}$ is located in the phase zone of titanium carbide in the Ti-C phase diagram, as shown in Figure 5 (Okamoto, 1998; SGTE). Thus, it is suggested that the phase in both sublayers in the $\mathrm{RZ}$ are titanium carbide (TiC). This is consistent with the SAED shown in Figures 4 (b)-(c). 


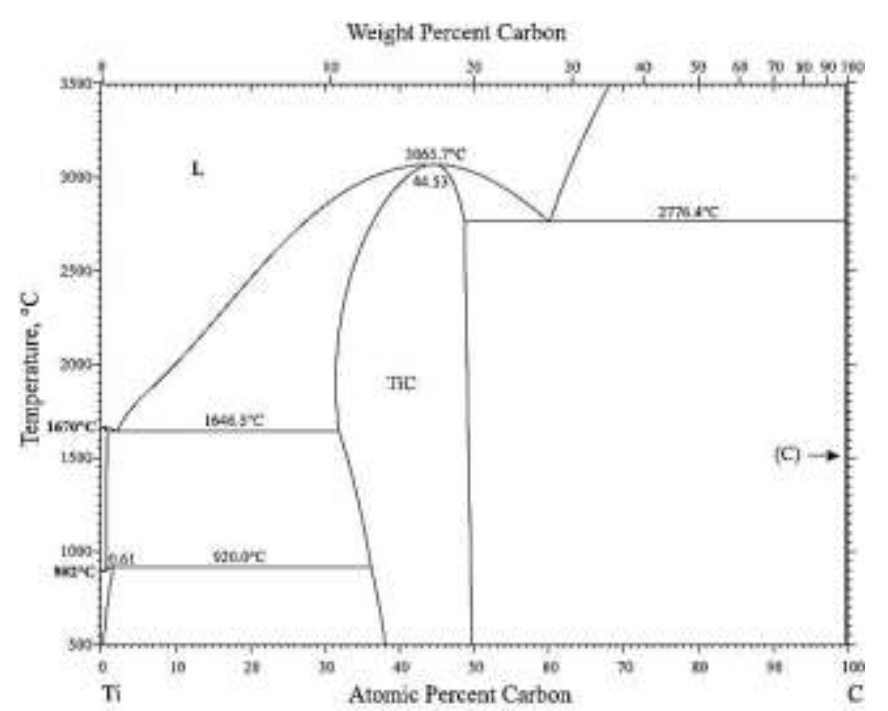

Figure 5 Ti-C phase diagram (Okamoto, 1998; SGTE), predicting the formation of TiC phase within the RZ

Table 2 Composition of RZ determined by EDS in TEM, the standard deviation is also included based on 5 measurements for each sublayer

\begin{tabular}{lllll}
\hline Atom fraction (\%) & C & Ti & Zr & Sn \\
\hline Fine-grained sublayer in the RZ & $48.0 \pm 0.6$ & $50.3 \pm 0.5$ & $0.8 \pm 0.1$ & $0.9 \pm 0.1$ \\
Coarse-grained sublayer in the RZ & $45.6 \pm 0.3$ & $53.0 \pm 0.4$ & $0.9 \pm 0.1$ & $0.5 \pm 0.1$ \\
\hline
\end{tabular}

The thicknesses of the RZ formed adjacent to both $\alpha$ and $\beta$ phases are statistically similar, ranging from $390 \mathrm{~nm}$ to $410 \mathrm{~nm}$, suggesting that the chemical reactions at both fibre $/ \alpha$ and fibre $/ \beta$ interfaces take place at similar rates. Therefore, the roughness of the reaction zone front is fairly small even though the reaction front is slightly irregular. This can be explained in the viewpoint of atom diffusion process during composite fabrication at high temperature, which induced the chemical reaction occurring at the interface forming the RZ. The diffusion of carbon and matrix atoms occurs at the fibre/matrix interfacial region in the composite, which is confirmed by the TEM/EDS linescan profiles shown in Figure 6. The linescan profiles were acquired across the interface following the lines marked in Figure 4 (a). Monte Carlo work by Belova and 
Murch (Mehrer, 2007) showed that lattice diffusion length needs to be only slightly larger than the spacing between grain boundaries. Thus, the diffusion fronts around neighbouring grain boundaries overlap and one moving atom may move to any grains and grain boundaries in adjacent during the HIP. This can also be described in terms of effective diffusivity of atoms in the composite system. The lattice diffusivity is smaller than the grain boundary diffusivity. But the enhancement due to grain boundaries is weakened by the elevated temperature since the activation energy of lattice diffusion is larger than that of the grain boundary diffusion. In such case, the effective diffusivity approaches the lattice diffusion at sufficiently high temperatures. Therefore, the irregularity of diffusion/reaction front formed at the elevated fabrication temperature is limited.

Figure 6 reveals clearly the elemental distribution at the fibre/matrix interface, therefore, the direction of atom diffusion within the fibre/matrix interfacial region. For either the fibre/RZ/ $\alpha$ phase interface shown in Figure 6 (a) and (b) or the fibre/RZ/ $\beta$ phase interface shown in Figure 6(c) and (d), $\mathrm{Ti}, \mathrm{Zr}$ and $\mathrm{Sn}$ atoms in the matrix have migrated into the $\mathrm{RZ}$ while $\mathrm{C}$ atoms from the coating have diffused in the opposite direction from the coating into the RZ. Ti and C are present in the entire RZ. However, $\mathrm{Zr}$ and $\mathrm{Sn}$ are only detected in the RZ region close to the RZ/fibre interface, appearing as small peaks in the linescan profiles shown in Figure 6. Scrutiny of the linescan profiles indicates that the $\mathrm{Zr}$ and $\mathrm{Sn}$ peaks appear at approximately $60 \mathrm{~nm}$ inside from the RZ/fibre interface, i.e. within the coarse-grained region adjacent to the fine-grained sublayer of the RZ. Thus, the accumulation of $\mathrm{Zr}$ and $\mathrm{Sn}$ at the particular region may be associated with the rejection of both atoms by the fine-grained sublayer. Further, the width of the $\mathrm{Zr}$ and $\mathrm{Sn}$ peaks are slightly different and the Sn peak extends further, indicating that there are a 
region containing both $\mathrm{Zr}$ and $\mathrm{Sn}$ and a region containing only $\mathrm{Sn}$ in addition to $\mathrm{C}$ and Ti. Further investigation will be undertaken to advance the understanding of the mechanism for the accumulation of $\mathrm{Zr}$ and $\mathrm{Sn}$ in the $\mathrm{RZ}$ in future work. However, atoms of $\mathrm{Al}, \mathrm{Cr}$ and Mo have not migrated into the RZ significantly. They remain within the matrix, as shown in Figure 6 (b) and (d). This is in good agreement with the results included in both Table 1 and Table 2 .

As shown in Table 2 and Figure 6, Si is not detected in the $\mathrm{RZ}$ or the $\mathrm{C}$ coating, suggesting that $\mathrm{Si}$ has not migrated across the $\mathrm{SiC} / \mathrm{C}$ interface from $\mathrm{SiC}$ into $\mathrm{C}$ coating. Further, $\mathrm{Al}, \mathrm{Cr}$ and Mo are not detected in the RZ, suggesting that these elements have been rejected out of the RZ. In the other respect, Table 1 shows that in either $\alpha$ phase or $\beta$ phase, the content of $\mathrm{Al}, \mathrm{Cr}$ and $\mathrm{Mo}$ in the region adjacent to the $\mathrm{RZ}$ is much higher than that within the bulk matrix. It is noteworthy that the content of $\mathrm{Al}$ in $\alpha$ phase in front of the RZ has increased more than twofold in comparison with that in the $\alpha$ phase within the bulk matrix and the content of Mo in $\beta$ phase adjacent to the $\mathrm{RZ}$ is nearly three times as high as that in $\beta$ phase within the bulk matrix. Evidently, Al, Mo and $\mathrm{Cr}$ atoms are rejected and piled up in the matrix in front of the RZ. The rejection of $\mathrm{Al}$ was observed previously in other $\mathrm{C}$-coated $\mathrm{SiC}$ fibre reinforced $\mathrm{Ti}$ alloy composites or $\mathrm{B}_{4} \mathrm{C} /$ boron-coated fibre reinforced Ti alloy systems (Hall and Lirn, 1992; Jeng et al., 1989; Martineau et al., 1984; Metcalfe, 1974). In addition to Al, the rejection of Mo and Cr is observed in this study. It has been well understood that the early transition metals such as $\mathrm{Ti}$ and $\mathrm{Zr}$ can interact with $\mathrm{C}$ much more easily to form carbide than the later transition metals such as Cr and Mo (Jansson and Lewin, 2013). Based on the composition of the Ti-17 matrix, there are five chemical reactions that may occur between $\mathrm{C}$ coating and metal atoms during the composite fabrication process, as 
expressed in Equations $2-6$. However, reaction between $\mathrm{Sn}$ and $\mathrm{C}$ has not been found in Ti-Sn-C systems after high-temperature consolidation from $800^{\circ}$ to $1200^{\circ} \mathrm{C}$ ( $\mathrm{Li}$ et al., 2006; Li et al., 2010).

$$
\begin{aligned}
& \mathrm{C}+\mathrm{Ti} \rightarrow \mathrm{TiC} \\
& \mathrm{C}+\mathrm{Zr} \rightarrow \mathrm{ZrC} \\
& \mathrm{C}+\mathrm{Cr} \rightarrow \mathrm{Cr}_{3} \mathrm{C}_{2} \\
& \mathrm{C}+\mathrm{Mo} \rightarrow \mathrm{Mo}_{2} \mathrm{C} \\
& \mathrm{C}+\mathrm{Al} \rightarrow \mathrm{Al}_{4} \mathrm{C}_{3}
\end{aligned}
$$$$
\text { ... ( } 4 \text { ) }
$$$$
\text { ... ( } 5 \text { ) }
$$$$
\ldots(6)
$$

The free energy change of the reactions expressed by Equations $2-6$ are approximately $-180 \mathrm{~kJ} / \mathrm{mol},-190 \mathrm{~kJ} / \mathrm{mol},-25 \mathrm{~kJ} / \mathrm{mol},-25 \mathrm{~kJ} / \mathrm{mol}$ and $7.4 \mathrm{~kJ} / \mathrm{mol}$ at $860^{\circ} \mathrm{C}$ respectively (Hall and Lirn, 1992; Pierson, 1996; Zhang et al., 2013). The reduction of the free energy for reactions 2 and 3 is significantly greater than that for other reactions. The free energy change for reactions 4 and 5 is close to zero and the free energy change for reaction 6 is positive. From the viewpoint of thermodynamics, reactions 2 and 3 are favoured to produce $\mathrm{TiC}$ and $\mathrm{ZrC}$ in the $\mathrm{RZ}$. Reactions $4-6$ are very difficult to occur. However, $\mathrm{ZrC}$ is not found in the $\mathrm{RZ}$ though trace content of $\mathrm{Zr}$ exists in the $\mathrm{RZ} . \mathrm{Zr}$ and Sn may be incorporated in the titanium carbide below $1400^{\circ} \mathrm{C}$ (Kerans et al., 1984), perhaps through substituting Ti, as revealed by EDS (Table 2 and Figure 6). Al, Mo and $\mathrm{Cr}$ are rejected out of the titanium carbide in the $\mathrm{RZ}$.

By contrast, in the Ti matrix composite systems containing SCS-6 or sigma fibres where the carbon coatings on the fibre surface contain $\mathrm{SiC}$ particles, titanium silicides $\left(\mathrm{Ti}_{5} \mathrm{Si}_{3}\right.$, $\mathrm{Ti}_{3} \mathrm{Si}$ ) and titanium aluminum carbide, in addition to titanium carbides, were also 
identified in the RZ due to the reaction between matrix atoms and atoms in the carbonrich coating ( including Si) (Dudek et al., 1997; Hall and Ni, 1995; Yang and Dudek, 1997; Yang et al., 1998b). In a more recent study on a hot-pressed SiC/Ti joints, the TEM observation showed the presence of $\mathrm{Ti}_{3} \mathrm{SiC}_{2}, \mathrm{Ti}_{5} \mathrm{Si}_{3} \mathrm{C}_{\mathrm{x}}$ and $\mathrm{TiSi}_{2}$ in the interface area due to the reaction between $\mathrm{SiC}$ and $\mathrm{Ti}$ at high temperatures (Halbig et al., 2012). In addition to the free energy change which determines the reactions occurring at the interface during HIP of the composite, the pressure used in the HIP may also influence the reaction by affecting the atom diffusion at the interface. It has been reported that the interstitial diffusion rate decreases with pressure, whereas the change of substitutional diffusion rate depends on atomic radius (Li et al., 2017; Werner et al., 1985; Yamane and Hisayuki, 1999). In this study, as shown in Table 2 and Figure 6, the rejection of Al, Mo and Cr out of the RZ may partly due to the diffusion inhibition caused by the high pressure applied on the composite during HIP, while for atoms $\mathrm{Ti}, \mathrm{Zr}$ and $\mathrm{Sn}$, the high pressure possibly helps promote the atom diffusion which results in the formation of titanium carbide in the RZ.

Element rejection has been regarded as an effective mechanism of reducing atom diffusion and, consequently, slowing down the reaction rate at the fibre/matrix interface(Metcalfe, 1974). Such reaction can result in fast thickening of RZ at high temperature, leading to the loss of the interface stability and degradation of mechanical properties of the composites at elevated temperatures (Hall and Ni, 1995; Yang and Dudek, 1997; Yang et al., 1998a; Yang et al., 1998b). Thus, the rejection of the major alloying elements $\mathrm{Al}, \mathrm{Mo}$ and $\mathrm{Cr}$ is beneficial to maintaining the compatibility and stability of the interface in this composite system. So is the barrier function of protective carbon coating on the fibre surface. The rejection of $\mathrm{Si}$ by the $\mathrm{C}$ coating avoids the 
reaction between $\mathrm{Si}$ and alloy matrix, which can easily occur and produce titanium silicide in the presence of $\mathrm{Si}$ and $\mathrm{Ti}$ at elevated temperatures.
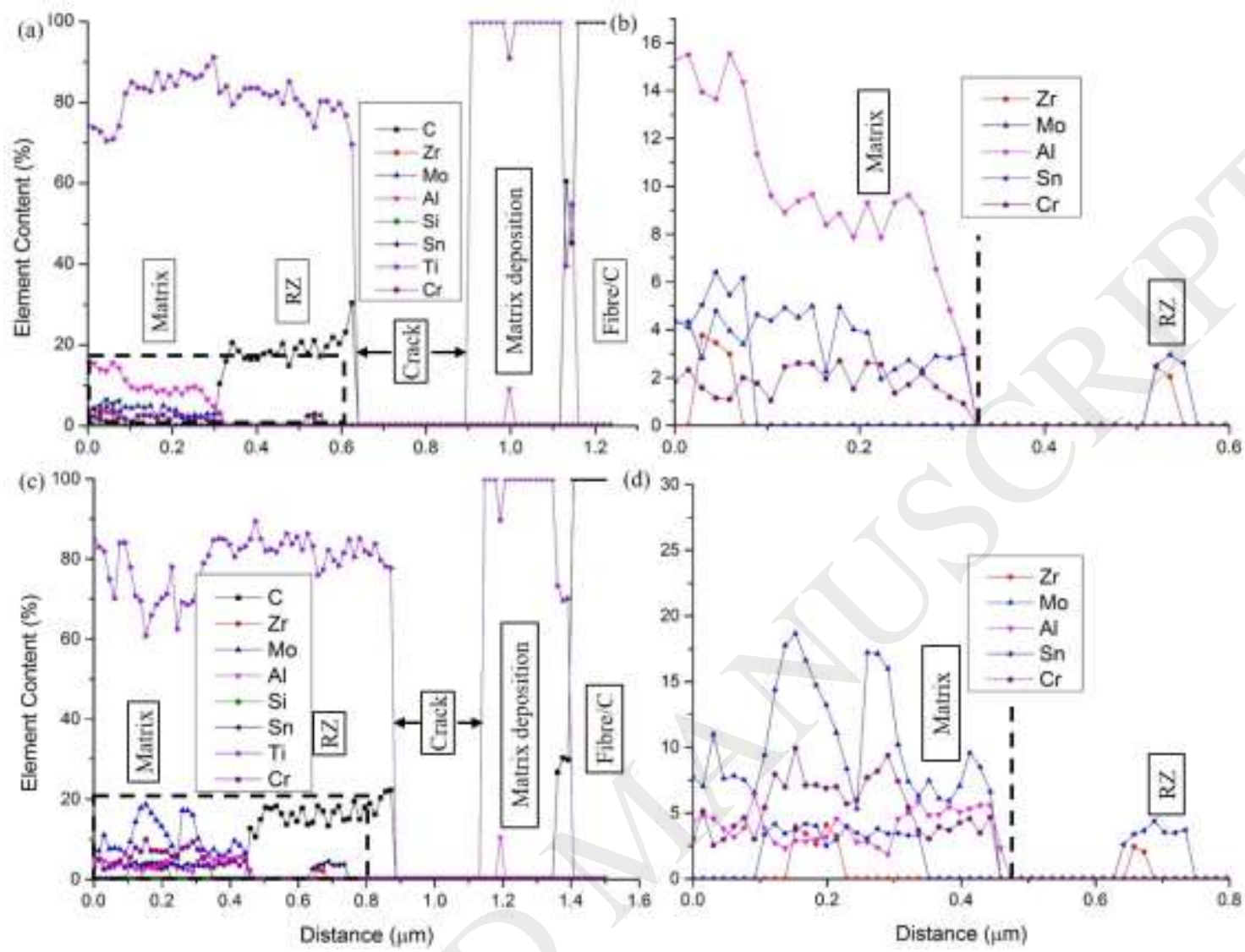

Figure 6 TEM/EDS linescan profiles: (a) followed the dashed line across the fibre/RZ/ $\alpha$ phase interface marked in Figure 4 (a), (b) the framed area in (a) at enlarged scale, and (c) followed the solid line across the fibre/RZ/ $\beta$ phase interface denoted in Figure 4 (a), (d) the framed area in (c) at enlarged scale, showing: (a),(c) the overview of the elemental distribution at the interfacial region and (b),(d) the diffusion of $\mathrm{Zr}$ and $\mathrm{Cr}$ into the $\mathrm{RZ}$ and rejection of $\mathrm{Al}, \mathrm{Cr}$ and $\mathrm{Mo}$ in front of the $\mathrm{RZ} /$ matrix interface. The vertical dashed lines in (b) and (d) indicate the border between RZ and matrix.

As briefly described above, artefact was introduced during TEM specimen preparation.

A Ti-rich layer exists next to carbon coating in the linescan profiles. The layer is believed to be resulted from the redeposition of sputtered matrix atoms ( $\mathrm{Ti}$ and $\mathrm{Al}$ ) onto the surfaces at the fibre/RZ crack that was introduced during specimen preparation before the specimen was being sputtered in PIPS. The redeposition layer is found immediately adjacent to the carbon coating, as shown in Figure 4, similar to the 
observation reported in literature (Jin et al., 2012; Rao et al., 2010). Further, a blank gap where no species were detected by the EDS is observed between the interfacial RZ and matrix redeposition layer in the linescan profiles, corresponding to the brightest band related to the separation denoted in Figure 4(a). The fibre/RZ interface cracking occurs due to the thermal residual stress release in the thin TEM specimen during ion milling. As described previously, the CTE mismatch between Ti matrix and the reinforcing SiC fibres (Bobet and Masuda, 1997; Mukherjee et al., 1997) can results in remarkable thermal residual stress in the composite after HIP, especially at the fibre/matrix interface regions. Meanwhile, the load that the TEM specimen can sustain is low since the specimen is extremely thin. Therefore, the cracking occurs at the weakest sites in the specimen, when the residual stress is higher than the strength of the interface.

Based on the observation described above, a structure model of fibre/matrix interface reaction zone is proposed to describe the formation of RZ, as illustrated in Figure 7. It is believed that the RZ formation proceeds in four stages. In stage I, the two original constituents of the composite, C-coated SiC fibre and Ti-17, are brought together. Their surfaces are being hot pressed to approach each other when the HIP process is initiated. The initial interface region forms between them denoted by the dashed line in Figure 7 (a). The surface contact between the fibre and matrix plays an important role in the following diffusion and chemical reaction stages. It determines the rates of diffusion and chemical reactions (Kostogorova et al., 2002; Kostogorova and Viljoen, 2003; Richter and Viljoen, 2002). 

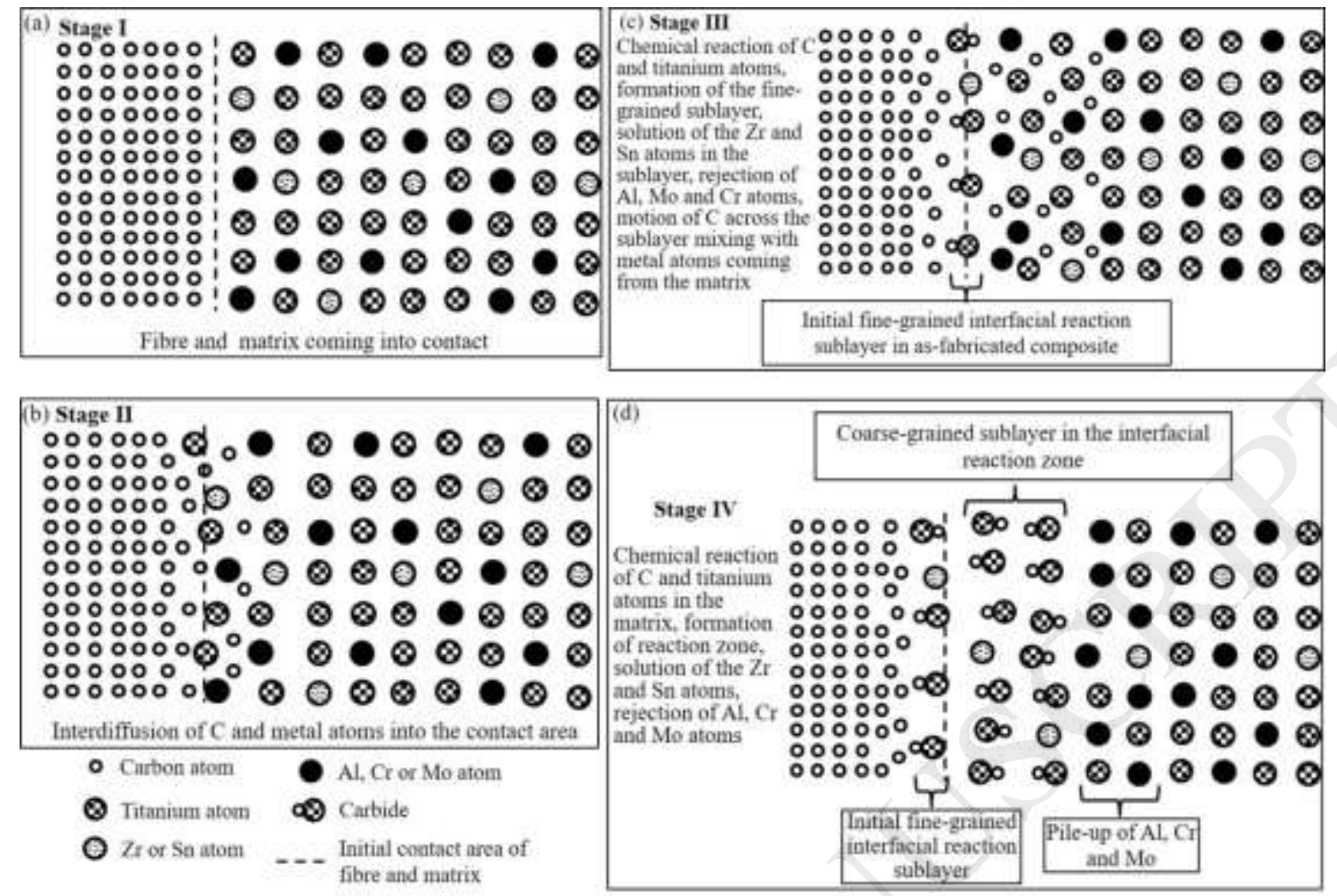

Figure 7 Structural model of RZ, describing the formation mechanism of the interface $\mathrm{RZ}$ in four stages

When the fibre and matrix come into contact at elevated temperatures employed in the HIP process, the atoms in both surfaces are excited, jumping out of the surface potential well and hop from the original sites to new sites across the interface. Both carbon atoms in the coating on the fibre and metal atoms in the alloy matrix are thermally activated (Gersten and Smith, 2001) and the diffusion of carbon atoms and metal atoms is initiated (Stage II in Figure 7 (b)). The so-called pseudo species [C $\mathrm{Ti}(\mathrm{Zr}, \mathrm{Sn})]$ are formed at the interfacial region, as illustrated in Equation 7(Rice, 1985).

$$
\mathrm{C}+\mathrm{Ti}(\mathrm{Zr}, \mathrm{Sn}) \leftrightarrow[\mathrm{C} \mathrm{Ti}(\mathrm{Zr}, \mathrm{Sn})]
$$

If the pseudo species $[\mathrm{C} \mathrm{Ti}(\mathrm{Zr}, \mathrm{Sn})]$ is at the saddle point of the surface potential energy, it can be described as an activated complex(Andrews et al., 1967; Borg and Dienes, 1988b; Martin et al., 1997; Rice, 1985). This description is schematically shown in 
Figure 8 . The state corresponding to the maximum of the energy barrier between the reactants and product is generally defined as the activated complex or transition state and also as the excited state. When the pseudo species exists at the excited state, the chemical reaction occurs to produce the new compound titanium carbide (Stage III in Figure 7 (c)). The chemical reaction proceeds as described by Equation 8, driven by the difference in free energy between the reactants and the product. In this stage, the carbide phase nucleates and grows in both directions for a very limited reaction time to form a layer of fine grains. Once the fine-grained sublayer is formed, the diffusion of the $\mathrm{Ti}$ atoms towards the carbon coating is halted by the fine-grained carbide sublayer since the interaction between the carbide and Ti can only be initiated above $1300^{\circ} \mathrm{C}$ (Strashinskaya, 1971), which is significantly higher than $860^{\circ} \mathrm{C}$ employed for the fabrication of the composite. Thus, the nucleation and growth of the initially formed fine-grained compounds is terminated. During this process, $\mathrm{Ti}$ is involved in the formation of the fine-grained compounds and $\mathrm{Al}, \mathrm{Cr}$ and $\mathrm{Mo}$ are rejected out of the sublayer since the former are energetically favoured. The thin sublayer composed of the fine grains is thus produced in this stage, which is revealed in Figure 4(a) and illustrated in the Stage III in Figure 7 (c).

$$
\mathrm{C}+\mathrm{Ti}(\mathrm{Zr}, \mathrm{Sn}) \leftrightarrow[\mathrm{C} \mathrm{Ti}(\mathrm{Zr}, \mathrm{Sn})] \rightarrow \mathrm{Ti}(\mathrm{Zr}, \mathrm{Sn}) \mathrm{C}
$$

The migration of $\mathrm{C}$ atoms carries on across the thin fine-grained sublayer to reach the fine-grained carbide sublayer/matrix interface. The migration of carbon atoms occurs in the interstitial diffusion mode because carbon atoms are considerably smaller than the matrix atoms. The migration of the metal atoms progresses with the mechanism of selfand substitutional solute diffusion namely collective mechanism (Borg and Dienes, 1988a; Gersten and Smith, 2001; Mehrer, 2007). The diffusion of the carbon atoms and 
matrix atoms yield a close configuration of the atoms staying in the excited state (Figure 8 and Equation 7) and produce the carbide product via chemical reaction denoted by Equation 8. The coarse-grained sublayer grows in the direction towards matrix until the HIP process terminated (Guo et al., 1998; Hall and Lirn, 1992; Naka et al., 1997; Zhang et al., 2003) . (Stage IV in Figure 7 (d)). The atoms of Al, Cr and Mo are rejected out of the RZ when this process advances. The coarse-grained sublayer in the RZ next to the matrix forms, as shown in Figure 3(b) and Figure 4 (a).

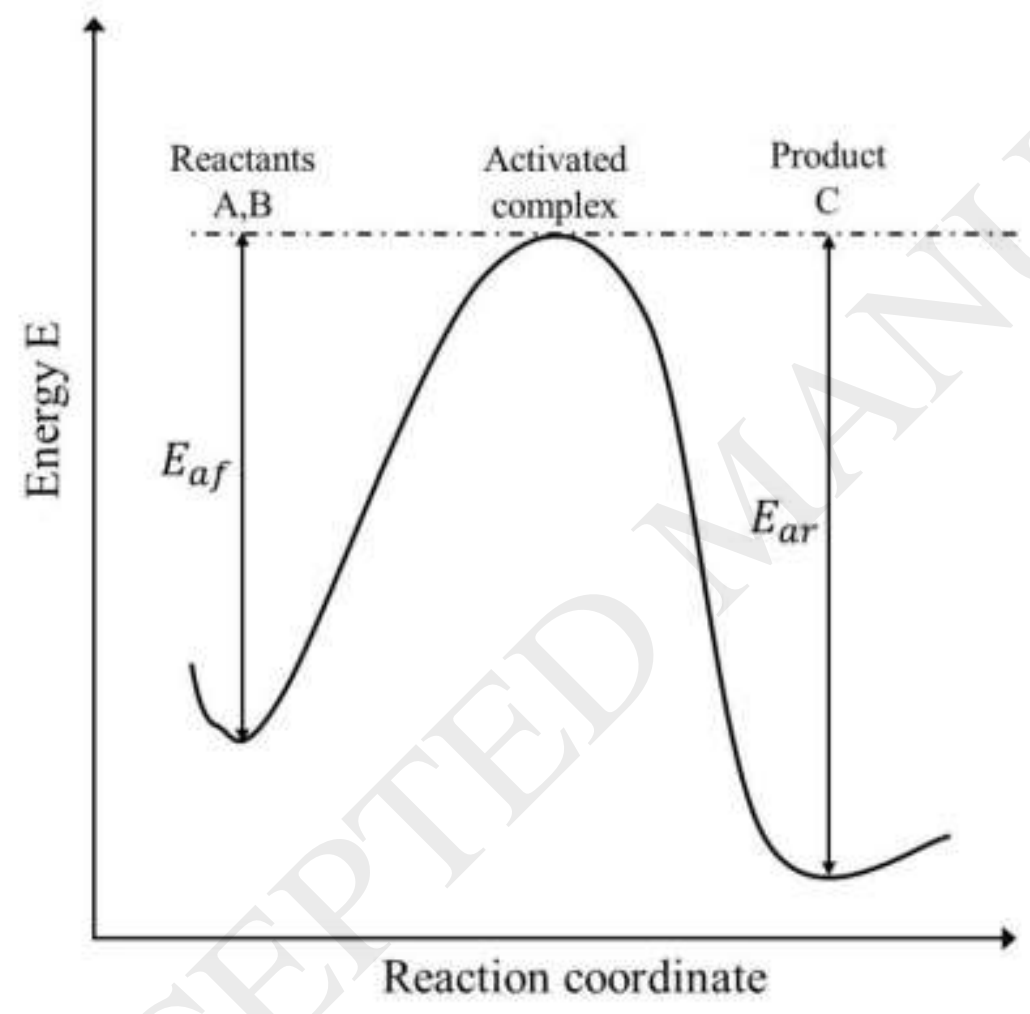

Figure 8 Two states of a reacting system corresponding to the reactants and the product, $\boldsymbol{E}_{\boldsymbol{a} \boldsymbol{f}}$ and $\boldsymbol{E}_{\boldsymbol{a r}}$ are activation energy of the forward reaction and reverse reaction respectively.

\section{Conclusions}

A well-defined two-layered reaction zone is formed at the fibre/matrix interface in the SiC fibre /Ti-17 composite under the selected fabrication conditions. The thickness of 
the reaction zone is $400 \mathrm{~nm}$, which is composed of two sublayers, a $60 \mathrm{~nm}$ thick finegrained sublayer and an approximate $340 \mathrm{~nm}$ thick coarse-grained sublayer. Both of the sublayers are identified as face-centred cubic titanium carbide.

The thicknesses of the RZ formed adjacent to both $\alpha$ and $\beta$ phases are statistically similar, suggesting that the reactions at both fibre $\alpha$ and fibre/ $\beta$ interfaces take place at similar rates.

$\mathrm{Al}, \mathrm{Mo}$ and $\mathrm{Cr}$ atoms in the matrix alloy are rejected out of the reaction zone and piled up in front of the interfacial reaction zone, which is beneficial to maintaining the compatibility and stability of the interface in this composite system by avoiding fast thickening of RZ.

$\mathrm{Zr}$ and $\mathrm{Sn}$ are present within the coarse-grained region adjacent to the fine-grained sublayer of the RZ.

A structural model describing the formation mechanism of fibre/matrix interfacial reaction zone is proposed. The model describes the reaction zone formation in four stages through atom diffusion and chemical reaction within the interfacial region.

\section{References}

Andrews, K.W., Dyson, D.J.,Keown, S.R., 1967. Interpretation of Electron Diffraction Patterns, Hilger \& Watts, London.

Bobet, J.L.,Masuda, C., 1997. Estimation of residual stresses in SiC/Ti-15-3 composites and their relaxation during a fatigue test. Journal of Materials Science. 32, 63576369.

Borg, R.J.,Dienes, G.J., 1988a. An Introduction to Solid State Diffusion, Academic Press Inc., London.

Borg, R.J.,Dienes, G.J., 1988b. An Introduction to Solid State Diffusion, Academic Press Inc., London. 
Campbell, F.C., 2012. Lightweight Materials - Understanding The Basics, ASM International, Russell.

Chou, T.W., Kelly, A.,Okura, A., 1985. Fibre-reinforced metal-matrix composites. Composites. 16, 187-206.

Dudek, H.J., Borath, R., Leucht, R.,Kaysser, W.A., 1997. Transmission electron microscopy of the fibre-matrix interface in SiC-SCS-6-fibre-reinforced IMI834 alloys. Journal of Materials Science. 32, 5355-5536.

Fan, Z., Guo, Z.X.,Cantor, B., 1997. The kinetics and mechanism of interfacial reaction in sigma fibre-reinforced Ti MMCs. Composites Part A. 28A, 131-140.

Fromentin, J.F., Debray, K., Petitcorps, Y.L., Martin, E.,Quenisset, J.M., 1996. Interfacial zone design in titanium-matrix composites reinforced by $\mathrm{SiC}$ filaments. Composites Science and Technology. 56, 767-775.

Gersten, J.I.,Smith, F.W., 2001. The Physics and Chemistry of Materials, John Wiley and Sons, Inc, New York.

Guo, S.Q., Kagawa, Y., Saito, H.,Masuda, C., 1998. Microstructural characterization of interface in $\mathrm{SiC}$ fiber-reinforced $\mathrm{Ti}-15 \mathrm{~V}-3 \mathrm{Cr}-3 \mathrm{Al}-3 \mathrm{Sn}$ matrix composite. Materials Science and Engineering: A. 246, 25-35.

Guo, Z.X., Derby, B.,Cantor, B., 1993. Comparison of interfaces in Ti composites reinforced with uncoated and $\mathrm{TiB}_{2} / \mathrm{C}$-coated $\mathrm{SiC}$ fibres. Journal of Microscopy. 169, 279-287.

Halbig, M.C., Singh, M.,Tsuda, H., 2012. Integration technologies for silicon carbidebased ceramics for micro-electro-mechanical systems-lean direct injector fuel injector applications. International journal of Applied Ceramic Technology. 9, 677-687.

Hall, I.W.,Lirn, J.-L., 1992. Microstructural analysis of isothermally exposed Ti/SiC metal matrix composites. Journal of Materials Science. 27, 3835-3842.

Hall, I.W.,Ni, C.Y., 1995. Thermal stability of an SCS-6/Ti-22Al-23Nb composite. Materials Science and Engineering: A. 192/193, 987-993.

Hull, D.,Clyne, T.W., 1996. An Introduction to Composite Materials, Cambridge Universtiy Press, Cambridge.

Jansson, U.,Lewin, E., 2013. Sputter deposition of transition-metal carbide films - A critical review from a chemical perspective. Thin Solid Films. 536, 1-24.

Jeng, S.M., Kai, W., Shih, C.J.,Yang, J.-M., 1989. Interface reaction studies of B4C/B and $\mathrm{SiC} / \mathrm{B}$ fiber-reinforced $\mathrm{Ti}_{3} \mathrm{Al}$ matrix composites. Materials Science and Engineering: A. 114, 189-196.

Jin, H.H., Cho, H.D., Kwon, S., Shin, C.,Kwon, J., 2012. Modified preparation technique of TEM sample for various TEM analyses of structural materials. Materials Letters. 89, 133-136.

Kerans, R.J., Mazdiyasni, K.S., Ruh, R.,Lipsitt, H.A., 1984. Solubility of metals in substoichiometric $\mathrm{TiC}_{1-\mathrm{x}}$. Journal of the American Ceramic Society. 67, 34-38.

Kostogorova, J., Viljoen, H.J.,Shteinberg, A., 2002. Role of particle geometry and surface contacts in solid-phase reactions. AIChE Journal. 48, 1794-1803.

Kostogorova, J.Y.,Viljoen, H.J., 2003. A macrokinetic study of the high-temperature solid-phase titanium-carbon reaction. Ind. Eng. Chem. Res. 42, 6714-6719.

Lacoste, E., Arvieu, C.,Quenisset, J.-M., 2015. Correlation between microstructures of SiC-reinforced titanium matrix composite and liquid route processing parameters. Journal of Materials Science. 50, 5583-5592. 
Li, H., Yang, C., Sun, L.,Li, M., 2017. Influence of pressure on interfacial microstructure evolution and atomic diffusion in the hot-press bonding of Ti33Al-3V to TC17. Journal of Alloys and Compounds. 720, 131-138.

Li, J., Wang, L., Qin, J., Chen, Y., Lu, W.,Zhang, D., 2011. The effect of heat treatment on thermal stability of Ti matrix composite. Journal of Alloys and Compounds. 509, $52-56$.

Li, S.B., Bei, G.P., Zhai, H.X.,Zhou, Y., 2006. Bimodal microstructure and reaction mechanism of $\mathrm{Ti}_{2} \mathrm{SnC}$ synthesized by a high-temperature reaction using $\mathrm{Ti} / \mathrm{Sn} / \mathrm{C}$ and $\mathrm{Ti} / \mathrm{Sn} / \mathrm{TiC}$ powder compacts. J. Am. Ceram. Soc. 89, 3617-3623.

Li, Y.X., Hu, J.D., Wang, H.Y.,Guo, Z.X., 2010. Effect of Sn addition on porosity and microstructure of products of self-propagating high temperature synthesis reaction of Al-Ti-C system. Materials Science and Technology. 26, 745-749.

Lissenden, C.J., Herakovich, C.T.,Pindera, M.J., 1995. Response of SiC/Ti under combined loading part I: Theory and experiment for imperfect bonding. Journal of Composite Materials. 29, 130-155.

Martin, J.W., Doherty, R.D.,Cantor, B., 1997. Stability of microstructure in metallic systems, Cambridge University Press, Cambridge.

Martineau, P., Lahaye, M., Pailler, R.,Naslain, R., 1984. SiC filament/titanium matrix composites regarded as model composites part 1 filament microanalysis and strength characterization. Journal of Materials Science. 19, 2731-2748.

Mehrer, H., 2007. Diffusion in Solids Fundamentals, Methods, Materials, Diffusioncontrolled Processes, Dordrecht : Springer.

Metcalfe, A.G., 1974. Interfaces in Metal Matrix Composites, Academic.

Mukherjee, S., Ananth, C.R.,Chandra, N., 1997. Effect of residual stresses on the interfacial fracture behavior of metal-matrix composites. Composite Science and Technology. 57, 1501-1512.

Naka, M., Feng, J.C.,Schuster, J.C., 1997. Phase reaction and diffusion path of the $\mathrm{SiC} / \mathrm{Ti}$ system. Metallurgical and Materials Transactions A. 28A, 1385-1390.

Ngai, T.W.L., Hu, C.X., Zheng, W., Xie, H.,Li, Y.Y., 2011. High temperature stability of SiC/Ti interface. Materials Science Forum. 685, 340-344.

Okamoto, H., 1998. C-Ti (Carbon-Titanium). Journal of Phase Equilibria. 19, 89.

Pierson, H.O., 1996. Handbook of Refractory Carbides and Nitrides, Noyes Publications.

Rao, D.V.S., Muraleedharan, K.,Humphreys, C.J., 2010. TEM specimen preparation techniques, In: Méndez-Vilas, A.,Díaz, J. (Eds.), Microscopy: Science, Technology, Applications and Education. FORMATEX, pp. 1232-1244.

Rice, S.A., 1985. Diffusion-Limited Reactions, Elsevier, Amsterdam.

Richter, C.,Viljoen, H.J., 2002. A combinatorial approach to surface contacts in solid phase reactions. Thermochimica Acta. 384, 315-328.

Saito, T., 2004. The automotive application of discontinuously reinforced TiB-Ti composites. JOM. 56, 33-36.

Scientific Group Thermodata Europe(SGTE), Binary (SGTE) alloy phase diagrams. http://www.sgte.org/fact/documentation/BINARY/BINARY_Figs.htm (accessed 18/07/2014)

Singerman, S.A.,Jackson, J.J. (1996) Titanium metal matrix composites for aerospace applications. In: Superalloys (eds. Kissinger, R.D., Deye, D.J., Anton, D.L., Cetel, A.D., Nathal, M.V., Pollock, T.M.,Woodford, D.A.). The Minerals, Metals and Materials Society, Anaheim. 
Strashinskaya, L.V., 1971. Contact interaction of titanium carbide with titanium, zirconium and vanadium in vacuo. Fiziko-Khimieheskaya Mekhanika Materialov. 7, 83-85.

Takahashi, N., Sato, T., Nakatsuka, S., Fujiwara, K., Yoshida, K., Yokozeki, T. (2012) Titanium metal matrix composite development for commercial aircraft landing gear structure. In: 28th International Congress of the Aeronautical Sciences. Brisbane.

Vassel, A., 1997. Interface considerations in high-temperature titanium metal matrix composites. Journal of Microscopy. 185, 303-309.

Werner, M., Mehrer, H.,Hochheimer, H.D., 1985. Effect of hydrostatic pressure and doping on self-diffusion in germanium. phys. Rev. B. 32, 3930-3937.

Xun, Y.W., Tan, M.J.,Zhou, J.T., 2000. Processing and interface stability of SiC fiber reinforced Ti-15V-3Cr matrix composites. Journal of Materials Processing Technology. 102, 215-220.

Yamane, T.,Hisayuki, K., 1999. Diffusion of platinum, vanadium, and manganese in $\mathrm{Ni}_{3} \mathrm{Al}$ phase under high pressure. Journal of Materials Science. 34, 1835-1838.

Yang, Y.Q.,Dudek, H.J., 1997. Interface stability in SCS-6 SiC/super $\alpha_{2}$ composites. Scripta Materialia. 37, 503-510.

Yang, Y.Q., Dudek, H.J.,Kumpfert, J., 1998a. Interfacial reaction and stability of SCS-6 $\mathrm{SiC} / \mathrm{Ti}-25 \mathrm{Al}-10 \mathrm{Nb}-3 \mathrm{~V}-1 \mathrm{Mo}$ composites. Materials Science and Engineering A246, 213-220.

Yang, Y.Q., Dudek, H.J.,Kumpfert, J., 1998b. TEM investigations of the fibre/matrix interface in SCS-6 SiC/Ti-25Al-10Nb-3V-1Mo composites. Composites Part A. 29A, 1235-1241.

Zhang, G., Kang, Q., Shi, N., Li, G.,Li, D., 2003. Kinetics and mechanism of interfacial reaction in a $\mathrm{SiC}_{\mathrm{f}} / \mathrm{Ti}$ composite. J. Mater. Sci. Technol. 19, 407-410.

Zhang, W., Yang, Y.Q., Zhao, G.M., Feng, Z.Q., Huang, B., Luo, X., Li, M.H.,Chen, Y.X., 2014. Interfacial reaction studies of $\mathrm{B}_{4} \mathrm{C}$-coated and C-coated $\mathrm{SiC}$ fiber reinforced Ti-43Al-9V composites. Intermetallics. 50, 14-19.

Zhang, W., Yang, Y.Q., Zhao, G.M., Huang, B., Feng, Z.Q., Luo, X., Li, M.H.,Lou, J.H., 2013. Investigation of interfacial reaction in SiC fiber reinforced Ti-43Al9V composites. Intermetallics. 33, 54-59.

Zhao, G.M., Yang, Y.Q., Zhang, W., Luo, X., Huang, B.,Chen, Y., 2013.

Microstructure and grain growth of the matrix of $\mathrm{SiC} / \mathrm{Ti}-6 \mathrm{Al}-4 \mathrm{~V}$ composites prepared by the consolidation of matrix-coated fibers in the $\beta$ phase field. Composites: Part B. 50, 155-163. 